\title{
Analysis of simultaneous time series of indoor, outdoor and soil air radon concentrations, meteorological and seismic data
}

Mirosław Janik, Peter Bossew

\begin{abstract}
It is well known that the temporal dynamic of indoor and outdoor radon concentrations show complex patterns, which are partly not easy to interpret. Clearly, for physical reasons, they must be related to possibly variable conditions of radon generation, migration and atmospheric dispersion and accumulation. The aim of this study was to analyse long-time series of simultaneously measured indoor and outdoor radon concentrations, together with environmental quantities, which may act as control variables of Rn. The study was performed in Chiba, Japan, using two ionization chambers for parallel indoor and outdoor radon concentrations measurements over 4 years. Meteorological and seismic data were obtained from the Japan Metrological Agency (JMA).
\end{abstract}

Key words: radon $\bullet$ time series $\bullet$ meteorological conditions $\bullet$ seismic

M. Janik

Department of Radiation Measurement

and Dose Assessment,

National Institute of Radiological Sciences,

4-9-1 Anagawa, Inage, Chiba 263-8555, Japan

P. Bossew

German Federal Office for Radiation Protection div. SW 1.1,

Köpenicker Allee 120-130, D-10318 Berlin, Germany, E-mail: pbossew@bfs.de

Received: 28 December 2015

Accepted: 6 April 2016

\section{Introduction}

Exposure to radon progenies is one of the most important sources of dose from ionizing radiation. This is especially valid in regions of the world where people spend much time indoors, because radon (here we restrict to ${ }^{222} \mathrm{Rn}$ and its progenies and put $\mathrm{Rn}$ for brevity) tends to accumulate indoors compared to the outdoor atmospheric environment. This importance has led to an immense wealth of studies and literature about Rn-related issues, over the decades. Amongst topics are understanding and modelling of temporal Rn dynamics as a function of environmental control parameters and the relations between $\mathrm{Rn}$ dynamics in different environmental compartments at one location. It also became clear that apart from its own radiological significance, $\mathrm{Rn}$ can serve as tracer for environmental processes and has been used in tectonic, hydrogeologic, atmospheric dispersion and climate change studies.

At the National Institute of Radiological Sciences (NIRS) in Chiba, near Tokyo, Japan, a long-term experiment of simultaneous measurement of indoor, outdoor and soil $\mathrm{Rn}$ concentrations has been ongoing for several years (soil Rn has been added only recently), together with recording meteorological and seismic parameters. The objective is (1) description of $\mathrm{Rn}$ concentrations and its dynamics in different environmental compartments; (2) studying the relationships between them and with environmental controls with the aim to develop a model of it, which has explanatory and predictive capability; and (3) to investigate whether the Rn signal carries information about tectonic activity. 


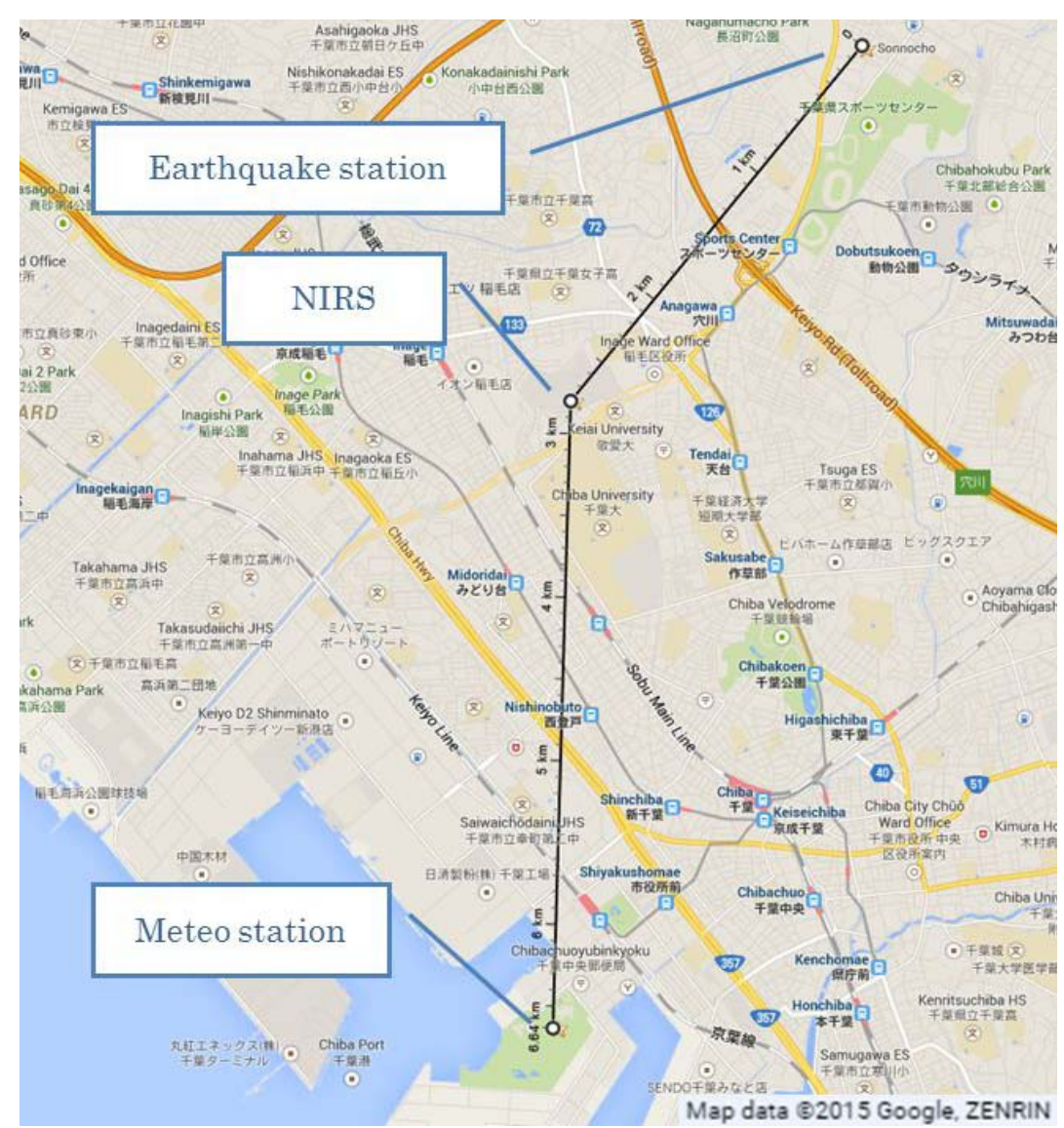

Fig. 1. Location of measurement points (based on Google maps).

In this contribution, we present the experimental setup and descriptive statistics of the results. Deeper analysis such as decomposition of periodicity, possible trend and correlation between the quantities will be addressed but not discussed extensively.

\section{Materials and experimental methods}

\section{Sampling locations}

The city of Chiba (about 1 million inhabitants) is located about $40 \mathrm{~km}$ East of Tokyo in a large, densely inhabited plain bordering the Tokyo Bay. In Inage Ward (district) of Chiba, the NIRS (http://www.nirs.go.jp/ ENG/index.shtml) is located, which has extensive radioanalytical facilities including $\mathrm{Rn}$ metrology. The location of measurement points are presented in Fig. 1.

Chiba has a humid subtropical climate with very warm and humid summers and cool and dry winters. Precipitation is significant throughout the year but is somewhat lower in winter (December-January) and summer (July-August). The annual cycle of monthly average meteorological conditions based on data from 1966 to 2015 are shown in Fig. 2. The maximum average relative humidity of $79 \%$ is registered in July, whereas minimum of 55\% in January. Average temperature is in the range from $1^{\circ} \mathrm{C}$ in January to $30^{\circ} \mathrm{C}$ in August. The highest precipitation with more than $180 \mathrm{~mm}$ is observed in September and October, whereas lowest, with less than $60 \mathrm{~mm}$, values are registered in winter season (December-January).

\section{Radon and thoron measurement}

Atmospheric and indoor radon concentrations have been continuously measured in the NIRS, Chiba, Japan (35 38'05"N, 140 06'06"E) from 4 February 2011 to 4 April 2015 using two AlphaGUARD ionization chambers [1].

The instrument for atmospheric radon is placed about $1.5 \mathrm{~m}$ above ground in the weather station box (Stevenson screen type) [2]. The indoor radon concentration is measured in a small storage room $\left(6.94 \mathrm{~m}^{3}\right)$ located in the basement of one research building, in the triangular or wedge-shaped void space at the bottom below a staircase. There is one


Fig. 2. Average monthly meteorological data in Chiba area (average 1966-2015; data from Japan Metrological Agency). 
small crawl entrance with usually closed door. This room has no window or other ventilation channel. The door does not close tightly, though.

Radon and thoron in soil gas are sampled from a depth of $0.5 \mathrm{~m}$ with a soil gas probe. Concentrations are determined with a RTM-2200 device [3]. The air with the flow rate of $0.3 \mathrm{l} / \mathrm{min}$ is transferred into the device by the internal pump of the RTM-2200, where the concentration of radon and thoron is continuously measured with 1 hour cycle.

AlphaGUARD and RTM-2200 are periodically checked in the NIRS radon and thoron chambers [4] as well as with samples of natural $\mathrm{U}$ and Th containing rock [5].

The uncertainty of measured Rn concentrations depends mainly on the number of counts during the counting period, 1 hour in our case. Additional uncertainty components may originate from the instrument background, calibration uncertainty and sampling effects, some of which appear as systematic errors in the final Rn values. The AlphaGUARD reports an uncertainty value to each measurement whose calculation is, however, complicated and not completely documented.

Outdoor ${ }^{222} \mathrm{Rn}$ concentrations can be very low, that is, a few becquerel per cubic metre, which is close to or below the nominal detection limit for individual measurements, about $2 \mathrm{~Bq} / \mathrm{m}^{3}$ according to the manufacturer. For the time being, we used the values returned by the instrument as they are, but we are aware of the problem. Detection limits of the AlphaGUARD cannot be derived the usual way from count rates. We plan to investigate the matter in a future study. Occasionally, the instrument returns negative $\mathrm{Rn}$ concentrations. These values were removed and set as missing values in the database. (We are aware that this can cause a statistical bias, but only relatively few values are concerned).

The time series are not complete because of the instrument failures and other events that prevented continuous measurement. This can cause problems in certain time series analyses.

\section{Meteorological and seismic data}

The metrological and seismic data, namely, wind speed and direction, precipitation, temperature, dew point, pressure, relative humidity as well as earthquake magnitude data, are obtained from the Japan Metrological Agency [6]. Stations are located about 3-4 km away from the NIRS in different directions (Fig. 1) but can be assumed to represent the conditions at the NIRS with accuracy which is sufficient for our purpose.

\section{Results and discussion}

\section{Descriptive statistics}

Nearly 37000 raw values of Rn concentrations inside and outside each together with meteorological data are available for evaluation. The AlphaGUARD for indoor radon measurement is located in a storage room, which is used from time to time. At these occasions, the door is kept open for a while, which leads to 'anomalous' results during these periods, if the configuration with closed door is considered the standard experimental situation. To correct for this effect, the raw collected data were manually revised and cleaned before further evaluation. The 'anomalous' data were removed if the simultaneous changes in radon concentration and humidity were significantly different from the trend, for example, radon dropped from $312 \mathrm{~Bq} / \mathrm{m}^{3}$ at 9.00 to $85 \mathrm{~Bq} / \mathrm{m}^{3}$ at 10.00 parallel with humidity changes. The cleaning procedure was continued until conditions in the storage room returned to the 'normal' trend.

The summaries of cleaned data are presented in Table 1 and Fig. 3.

Radon concentrations vary from 20 to $1256 \mathrm{~Bq} / \mathrm{m}^{3}$ and from 2 to $24 \mathrm{~Bq} / \mathrm{m}^{3}$ inside and outside, respectively. Previous study of indoor radon levels in Japan based on 3461 measurements in 3900 houses gave an arithmetic mean of $14 \mathrm{~Bq} / \mathrm{m}^{3}$ with $14 \mathrm{~Bq} / \mathrm{m}^{3}$ standard deviation [7]. Based on this survey, it was

(a)

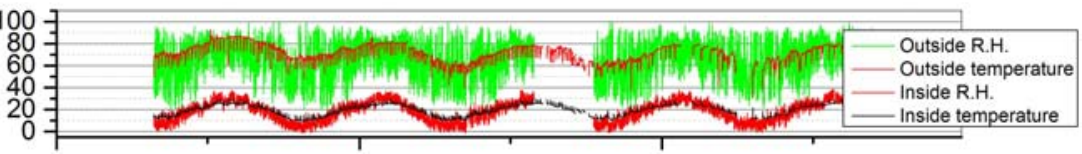

(b)

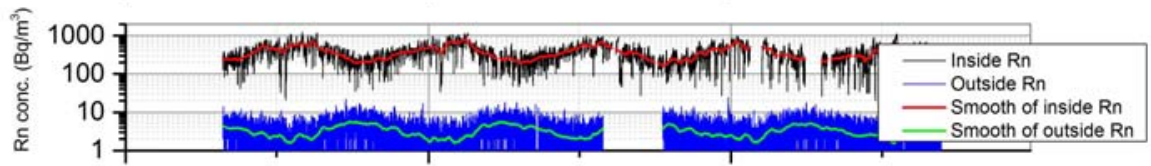

(c)

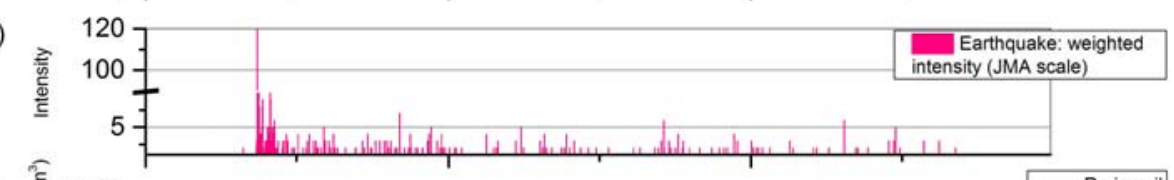

(d)

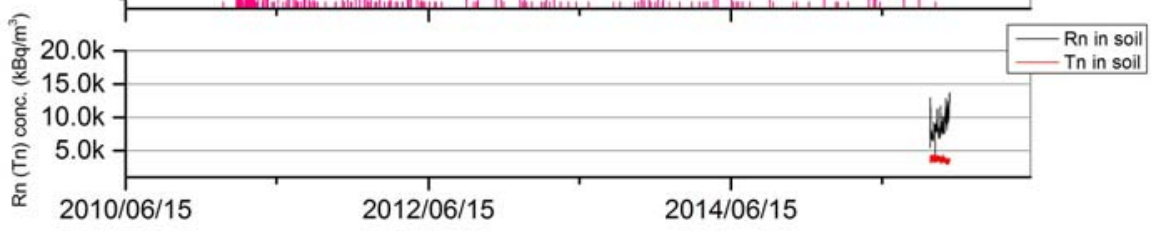

Fig. 3. Summary graph (a) temperature and relative humidity inside and outside, (b) radon concentration inside and outside (raw and smoothing using Savitzky-Golay filtering procedure), (c) earthquake normalized by weighted intensity (JMA scale) and (d) radon and thoron concentration in soil. 


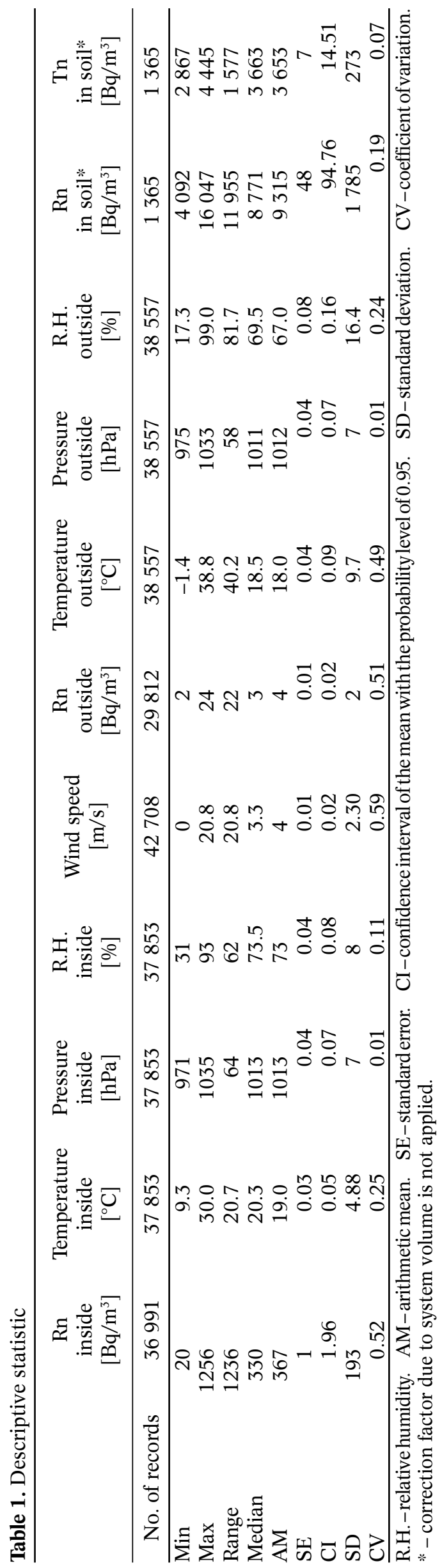

estimated that only $0.1 \%$ of dwellings in Japan exceed $100 \mathrm{~Bq} / \mathrm{m}^{3}$ radon concentration, which the WHO suggests as a reference level for indoor radon [8]. On the other hand, 'radon hot-spots' on Okinawa Island with relatively high indoor radon concentration, exceeded $300 \mathrm{~Bq} / \mathrm{m}^{3}$, described by Kranrod [9] was found. Moreover, from the long-term survey performed by Kobayashi [10], the radon concentration in a house located near Futsukaichi hot spring ranged from 14 to $184 \mathrm{~Bq} / \mathrm{m}^{3}$ with an arithmetic mean of $45 \mathrm{~Bq} / \mathrm{m}^{3}$.

The annual mean of radon outdoor in Japan was reported by Oikawa [11]. The experiment was carried out throughout Japan from 1997 to 1999 and a geographical-temporal mean value of about $6 \mathrm{~Bq} / \mathrm{m}^{3}$ was found.

Results of the current study indicate that average indoor radon concentration in the investigated room is 20 times higher than the average for Japanese dwellings. However, the investigated room is neither typical for residential rooms nor is the NIRS research building typical for residential houses. Therefore, the results cannot be taken as typical for the Rn dynamics in Japanese, or any dwellings. The outside value of radon is in good agreement with previous studies.

It should be noted that indoor radon concentration is magnitudes higher than outdoor levels. Of course, this phenomenon has been known for long, but it is stronger in the investigated building than usual in Japan [7, 10-13] and more similar to what can be observed in Europe [14-18]. It suggests some particular mechanism of infiltration from indoor sources or from the ground and accumulation in that room, whose nature has not been understood so far. By screening in 'sniffing' mode no local Rn source inside that room or in its floor could be found. In addition, the gamma dose rate in the storage room is measured in the range from 90 to $100 \mathrm{nSv} / \mathrm{h}$, which is the same level as for the rest of the building. The presence of building materials with particularly high Ra content can therefore not be assumed. Figure 3 shows the annual periodicity of indoor and outdoor radon concentrations as well as environmental parameters. The maximum indoor radon concentration is observed in summer, whereas the maximum outdoor radon concentration is reached in winter. The values seem to be negatively correlated based on calculated Pearson's product-moment correlation coefficient (hereafter called correlation coefficient) as -0.18 .

On the other hand, significant correlations in relation amongst radon concentration and environmental parameters were observed, for example, correlation between radon inside and outside temperature is 0.55 , whereas the correlation between radon inside and gradient of temperature is 0.48 .

\section{Trend and periodicity}

Detailed investigation of radon data series reveals several periodical components of the Rn series. Figure 4 shows diurnal and annual cycles of indoor and outdoor radon concentrations. These 3D graphs were prepared using OriginLab software [19] based 
(a)

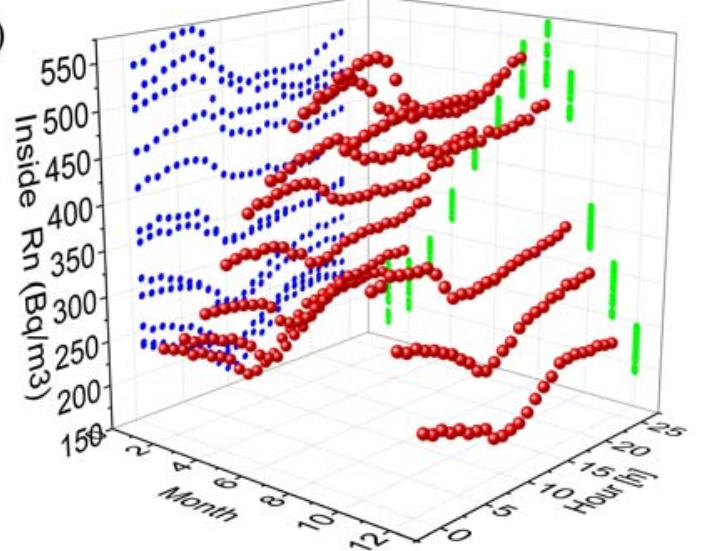

(c)

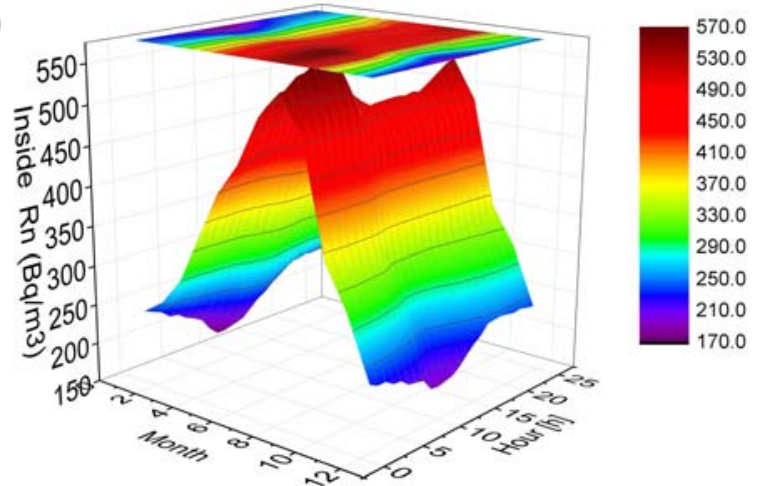

(b)



(d)

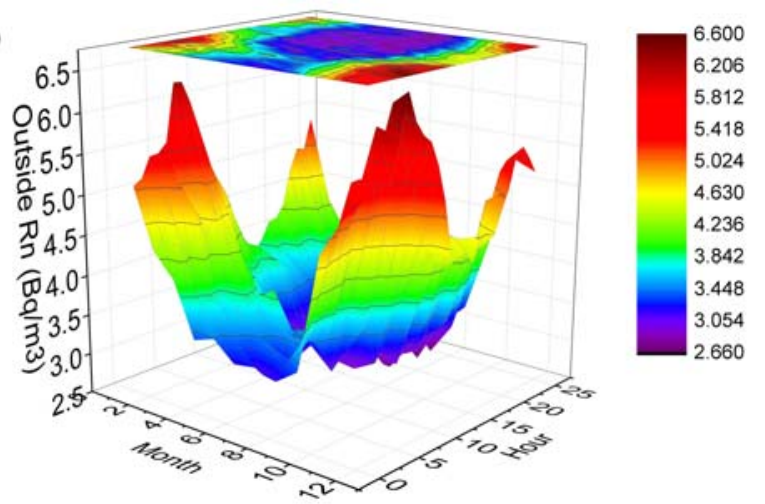

Fig. 4. 3D graph of monthly and hourly variations of the Rn (a) and (c) inside, (b) and (d) outside.

on data manipulated by scripts written in R-project [20] and R-Studio [21].

This type of graph allows easy visualization of two different periodicities present in the series and of the differences between the series. On the $x-y$, plane, months of the year ( $x$-axis) and hours of the day ( $y$-axis) are presented. The radon concentration data, which are shown on the $z$-axis, were calculated as averages over the entire series for a particular month and a particular hour. The monthly ( $x-z$ plane) and daily ( $y-z$ plane) trends of radon concentrations are clearly visible, in Figs. 4a and 4c, respectively. Diurnal variations of indoor and outdoor concentration, with maximum at night and minimum at daytime, are observed; however, the changes are more pronounced in the case of outdoor radon. In addition,

(a)

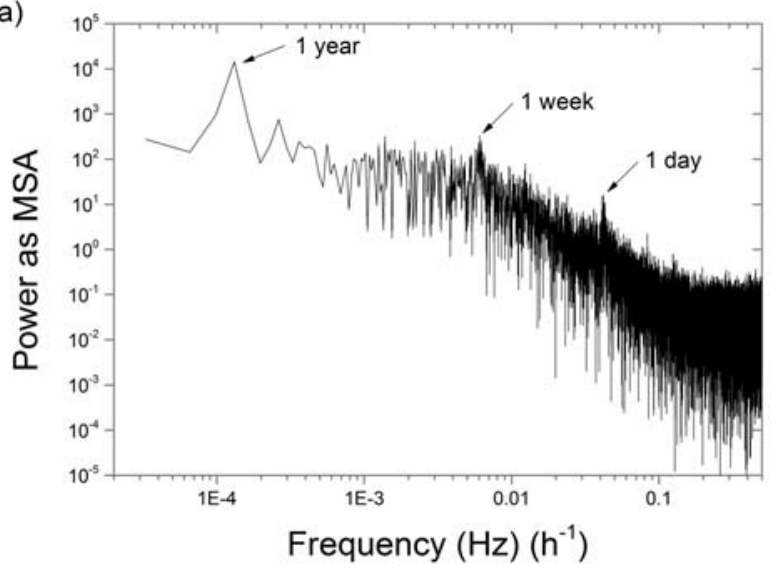

for the outdoor radon, the monthly gradient is higher in summer than in winter, whereas for the indoor radon, this effect is less clear. One can also recognize that in daily cycles, radon rapidly decreases around 7 a.m. and increases around 3 p.m. in the outdoor case, but for indoor case, it rapidly decreases at the same time but starts to increase slowly around noon. This diurnal variation effect can be connected very closely to the pattern of variation in inside and outside temperature difference with correlation coefficient 0.48 .

Periodicity is commonly analysed by Fourier transform. The results for indoor and outdoor Rn concentrations are shown in Fig. 5. The power spectrum is the graph of the absolute square of the Fourier transform in dependence of frequency; spec-

(b)

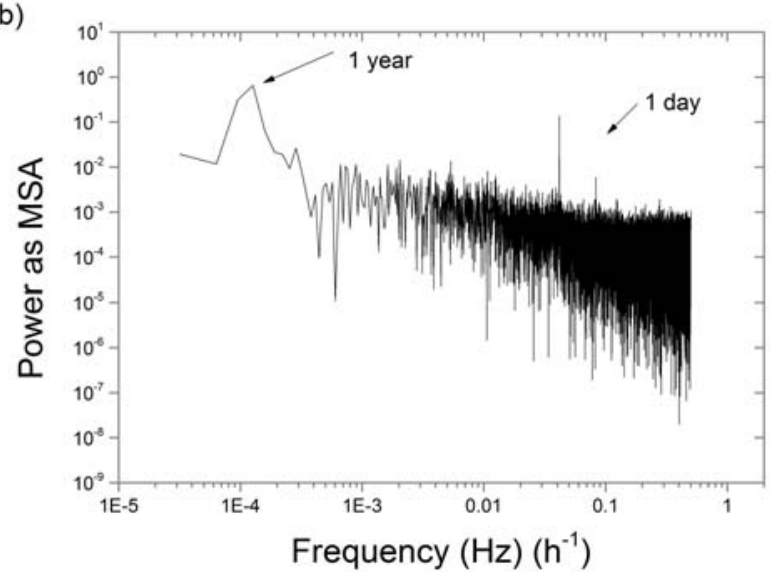

Fig. 5. Power as MSA (mean square amplitude) spectra of indoor (a) and outdoor (b) Rn concentrations. 




Fig. 6. Pearson correlation of indoor Rn concentration and outdoor temperature a number of hours before.

tral lines indicate main periodicities. Both graphs show the obvious daily and annual periods. Indoor $\mathrm{Rn}$ has a weekly period in addition, to be explained by that during weekend ventilation and turbulence is lower in the building. The slopes of the spectral functions are different: a flatter slope (outdoor $\mathrm{Rn}$ ) indicates the presence of more noise in the series.

\section{Dependence of radon on environmental variables}

Time series plots show the statistical dependence of indoor and outdoor $\mathrm{Rn}$ concentrations on environmental variables. However, the presence of periodicities can obscure the dependence structure. For example, the long-term time series of indoor Rn concentration and outdoor (or indoor) temperature show that they oscillate in the same pace, with both highest in summer. A closer look reveals that the dependencies are lagged, that is, highest correlations are attained if the series are shifted against each other for a number of time steps. As an example, Fig. 6 shows the squared Pearson correlation between indoor Rn concentration at time $t, \operatorname{Rn}(t)$ with outdoor temperature measured by the meteo station some hours before, $T(t-h)$, where $h$ denotes the lag. The highest correlation between indoor Rn appears with the temperature measured between 10 and 12 hours earlier. This means that for the daily cycle, indoor Rn and temperature are negatively correlated, that is, Rn concentrations are higher at night when temperatures are lower.

The latter effect is well known; activity of people during the day causes stronger turbulence and ventilation, so that the $\mathrm{Rn}$ in this room is so to say diluted, while it can build up at night. The former effect - higher indoor Rn in summer - must have its origin in the response of the overall air dynamic in the building to temperature. Perhaps stronger temperature-driven convection (stack effect) leads to a higher rate of $\mathrm{Rn}$ infiltration into the building from the ground; but this could be proven only if sources of $\mathrm{Rn}$ infiltration could be identified and Rn flux quantified, which has not been done yet.

One also has to consider that physical systems have inertia, so that state variables such as Rn concentration react with delay to their physical causes.
Given the interdependence of the environmental variables, it is difficult to find out by statistical means which is the main physical factor that controls the $\mathrm{Rn}$ dynamic. It appears that indoor and outdoor $\mathrm{Rn}$ concentrations are strongest positively or negatively correlated with temperature.

For example, a similar analysis as shown in Fig. 6, but replacing outside temperature by outside pressure, reveals maximum correlation (negative, in this case) for lag $=-1 \mathrm{~h}$. Further, regressing indoor $\mathrm{Rn}$ as dependent against outdoor temperature and pressure as independent variables yields maximum coefficient of determination $R^{2}$ (replacing the correlation coefficient in this statistical setting) for $\operatorname{lag}($ temperature $)=-11$ and $\operatorname{lag}($ pressure $)=0 \mathrm{~h}$.

As notation, define the lag operator $L_{T}$, which shifts a series $z(t)$ to $\left(L_{T} z\right)(t):=z(t-T)$.

Including more covariates as independent predictors (e.g. humidity) leads to even higher $R^{2}$ with again other optimal lags; on the other hand, the gain in fit (higher $R^{2}$ or lower RSS) may be counterbalanced by increased model complexity, so that the Akaike coefficient (or another measure of model performance) deteriorates with adding covariates in spite of increased $R^{2}$. Also choosing regression algorithms different from ordinary least square that are better suited for heteroskedastic data leads to different results.

These considerations are relevant if one attempts predicting missing $\mathrm{Rn}$ values from meteorological variables. One may, for example, choose a model $f\left(x_{i}\right), x_{i}$ the predictors, where $f$ possibly includes lag operators, and predict Rn as

$$
z=f\left(x_{j}\right)+\varepsilon, \varepsilon \sim N\left(0, \sigma^{2}\right)
$$

with $\varepsilon$ at each time step sampled independently from $N\left(0, \sigma^{2}\right), \sigma^{2}=s^{2}$ (regression) the residual variance $(s \text { (regr })^{2}=\mathrm{RSS} /(n-k-1)$ for $k$ predictors $)$, representing noise. A condition is that the regression residuals are normal and not serially correlated.

We plan to investigate optimal model selection for $\mathrm{Rn}$ prediction in the future in more detail.

\section{Possible seismic signals}

Radon concentration is considered as quantity that possibly reacts to seismic activity. The reason is that seismic or tectonic activity can induce variability of geogenic Rn flux, in turn a result of varying ground permeability. A seismic signal should manifest in a short-term anomaly in the residual Rn time series, if trend and periodic components have been removed.

We estimate short-term anomalies in the $\mathrm{Rn}$ series $z(t)$ by applying a filter $w$ :

$$
y(t)=\sum_{(j=-j 0 \ldots j 0)} w_{j} z(t-j)
$$

where $2 j_{0}+1$ is the practical size of the filter. The series of interest is the residual, $\operatorname{res}(t)=z(t)-y(t)$. In vector notation, this can be written as

$$
\text { res }=(I-\langle w, L\rangle) z
$$




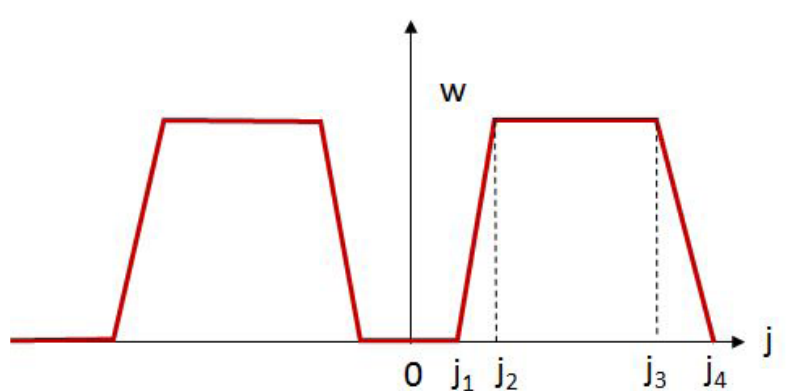

Fig. 7. Filter for recovering local anomalies.

with $I$ the identity, $L$ the lag operator and \langle\rangle the scalar product. The filter is chosen such as to calculate the local mean in a given period but excepting the target point $z(t)$, that is, $j=0$. The very simple, symmetrical filter function is shown in Fig. 7 . The chosen parameters are $j_{1}=2, j_{2}=3, j_{3}=25$ and $j_{4}=26$ hours. The filter is applied to the log-transformed series to mitigate heteroskedasticity.

The result for indoor and outdoor Rn concentration series is shown in Fig. 8 together with the seismic signals. (The seismic intensities are available on a daily base only and nominally refer to 00:00 of each day in the graphs. They are calculated as weighted sums of the values given in the Japan Meteorological Agency (JMA) scale [22], which classifies ground acceleration. There are seven JMA levels with additionally '5-lower' and '6-lower', which are assigned level values 4.5 and 5.5 here. The seismic database records numbers of shocks per level per day. We calculate a weighted sum of these shocks per day. This is a deliberate choice but the result does not depend on it. The figures show the series between February and June 2011, including the Great Tohoku Earthquake, 11 March 2011, which had magnitude 5-lower in Chiba. Aftershocks in the subsequent days are also visible in the graphs.

Visually, for both series, no correlation with the seismic signals appears present. One of the information is missing to us yet, however: the location of the epicentre, which may be relevant because distant earthquakes - even if they can be sensed very strongly, as for the Tohoku earthquake in Chiba - may not result in local tectonic anomalies in the ground that give rise to anomalous Rn flux.

Further, one would expect a clearer seismic response in the ground $\mathrm{Rn}$ concentration than in indoor or outdoor Rn. So far, our ground Rn series is still too short to enable statistical evaluation. However, we plan to investigate these issues further as more data are available.

\section{Conclusions}

Based on the data recorded so far, it is concluded that variation of indoor and outdoor radon concentrations depend on metrological factors to varying degrees, correlated positively or negatively, directly or with time lag. The Rn series show distinct cycles according the climatic periodicities. Indoor Rn, in addition, shows the influence of temporal occupation and usage patterns of the building. However, as an office and laboratory building, its Rn characteristic cannot be assumed representative of residential

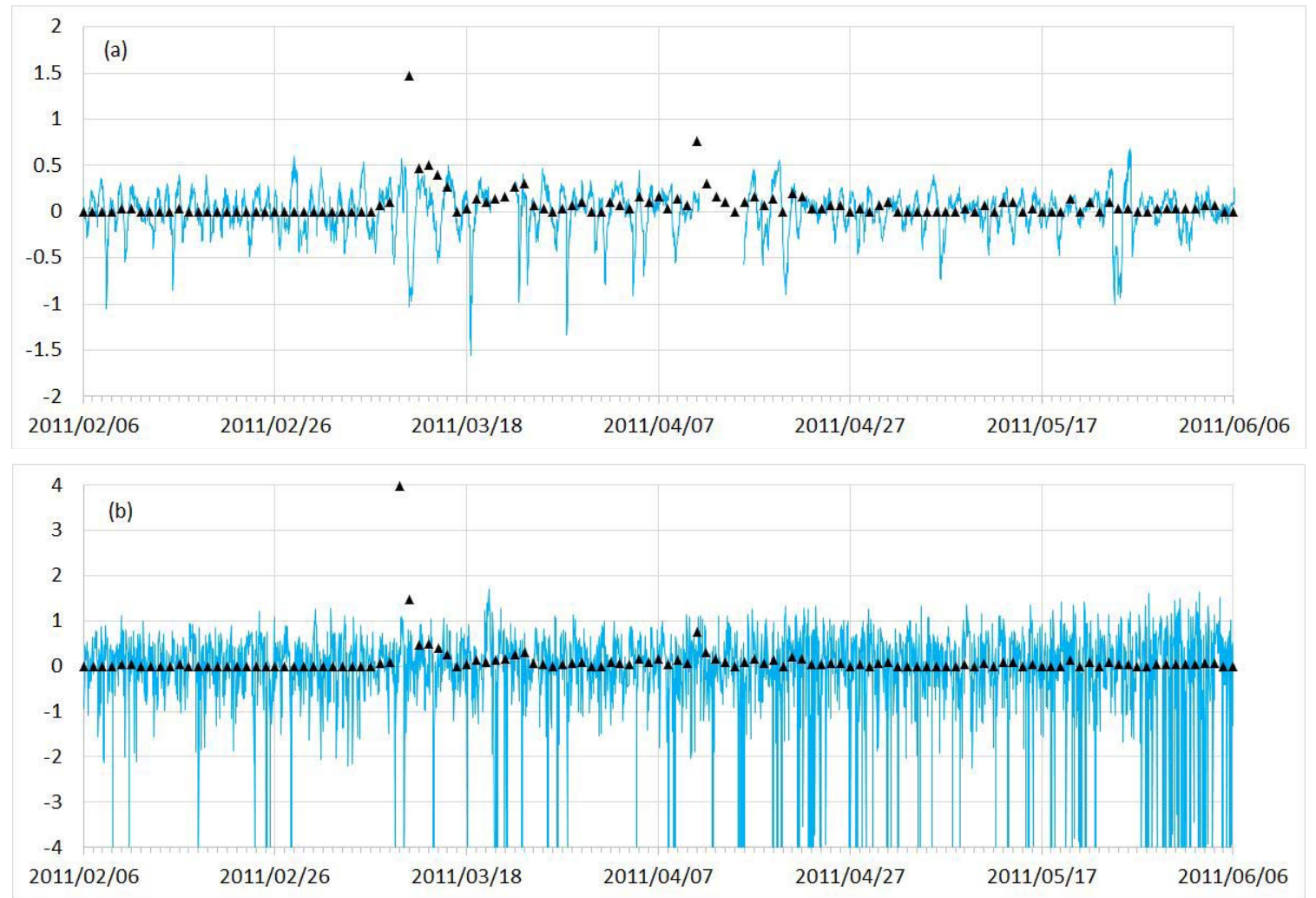

Fig. 8. Blue graphs: Filter (Fig. 7) applied to time series of indoor (a) and outdoor (b) Rn concentrations. Only short subseries of the entire series are shown for better readability. Values scaled deliberately. Black triangles: weighted seismic intensity. The Great Tohoku Earthquake on 11 March 2011 is clearly visible. 
buildings. So far, the analysis did not reveal a $\mathrm{Rn}$ response to seismic events; in particular the Great Tohoku Earthquake on 11 March 2011, which was felt very strongly in Chiba, did not leave traces in the indoor and outdoor Rn signals.

We plan to continue the measurements, including the soil $\mathrm{Rn}$ concentration that has been started in autumn 2015; the series is still too short for temporal analysis, but we expect it to react more sensitively to seismic signals than indoor or outdoor Rn, if such reaction exists at all. We also plan to deepen the statistical analysis by applying more advanced tools, such as seasonal adjustment (separating variability components), investigation of the lagged dependence structure of the individual variables (autocorrelation and partial autocorrelation) and their autoregressive properties. Further, the dependence on meteorological variables shall be studied in depth with the tentative aim of predicting indoor and outdoor Rn from these controls. Investigating the residuals around such model would also enable identification of possible additional non-meteorological controls on $\mathrm{Rn}$, which remain hidden in the raw series.

\section{References}

1. SAPHYMO GmbH. (2015). AlphaGUARD Professional radon monitor. Retrieved December 22, 2015, from http://www.saphymo.com/radiation-measurement/environmental-radiation-monitoring-systems/ alphaguard/154.htm.

2. Burt, S. (2012). The weather observer's handbook. Cambridge University Press.

3. SARAD GmbH. (2015). RTM 2200 - Radon and thoron measurement system. Retrieved December 22, 2015, from http://sarad.de/product-detail. php?lang $=$ en_US\&catID $=\&$ p_ID $=25$.

4. Tokonami, S., Ishikawa, T., Sorimachi, A., Takahashi, H., \& Miyahara, N. (2008). The Japanese radon and thoron reference chambers. AIP Conf. Proc., 1034, 202-205. Retrieved from http://scitation.aip.org/ content/aip/proceeding/aipcp/10.1063/1.2991208.

5. Durridge. (2015). Natural rock sample. Retrieved November 27, 2015, from http://www.durridge.com/ products_natural_rock_sample.shtml.

6. Japan Méteorogical Agency. (2015). Japan Meteorogical Agency. Retrieved January 19, 2015, from http:// www.jma.go.jp.

7. Suzuki, G., Yamaguchi, I., Ogata, H., Sugiyama, H., Yonehara, H., Kasagi, F., Fujiwara, S., Tatsukawa, J., Mori, I., \& Kimura, S. (2010). A nation-wide survey on indoor radon from 2007 to 2010 in Japan. J. Radiat. Res., 51(6), 683-689. Retrieved December 19, 2014, from http://joi.jlc.jst.go.jp/JST.JSTAGE/ jrr/10083? from $=$ CrossRef.

8. World Health Organization. (2009). WHO handbook on indoor radon - a public health perspective. Geneva: WHO.
9. Kranrod, C., Tokonami, S., Ishikawa, T., Sorimachi, A., Janik, M., Shingaki, R., Furukawa, M., Chanyotha, S., \& Chankow, N. (2009). Mitigation of the effective dose of radon decay products through the use of an air cleaner in a dwelling in Okinawa, Japan. Appl. Radiat. Isot., 67(6), 1127-1132. DOI: 10.1016/j. apradiso.2009.02.087.

10. Kobayashi, Y., Tokonami, S., Narazaki, Y., Zhuo, W., \& Furukawa, M. (2005). Enhanced indoor radon concentration by using radon-rich well water in a Japanese wooden house in Fukuoka, Japan. I. Radioanal. Nucl. Chem., 266(3), 389-396. Retrieved from http://dx.doi.org/10.1007/s10967-005-0922-3.

11. Oikawa, S., Kanno, N., Sanada, T., Ohashi, N., Uesugi, M., Sato, K., Abukawa, J., \& Higuchi, H. (2003). A nationwide survey of outdoor radon concentration in Japan. J. Environ. Radioact., 65(2), 203-213. DOI: 10.1016/S0265-931X(02)00097-8 .

12. Sanada, T., Fujimoto, K., Miyano, K., Doi, M., Tokonami, S., Uesugi, M., \& Takata, Y. (1999). Measurement of nationwide indoor Rn concentration in Japan. J. Environ. Radioact., 45(2), 129-137. DOI: 10.1016/ S0265-931X(02)00097-8.

13. Doi, M., \& Kobayashi, S. (1996). Surveys of concentration of radon isotopes in indoor and outdoor air in Japan. Environ. Int., 22(Suppl. 1), 649-655. Retrieved from http://www.sciencedirect.com/science/article/ pii/S0160412096001675.

14. Uyttenhove, J., \& Lapere, R. (1988). Long-term observations of indoor and outdoor radon concentrations Radiat. Prot. Dosim., 24(1/4), 435-437.

15. Gunning, G. A., Pollard, D., \& Finch, E. C. (2014). An outdoor radon survey and minimizing the uncertainties in low level measurements using CR-39 detectors. J. Radiol. Prot., 34(2), 457.

16. Vaupotič, J., Kobal, I., \& Križman, M. J. (2010). Background outdoor radon levels in Slovenia. Nukleonika, 55(4), 579-582.

17. Kümmel, M., Dushe, C., Müller, S., \& Gehrcke, K. (2014). Outdoor ${ }^{222} \mathrm{Rn}$-concentrations in Germany - part 1 - natural background. J. Environ. Radioact., 132, 123-130. http://dx.doi.org/10.1016/j.jenvrad.2014.01.012.

18. Kümmel, M., Dushe, C., Müller, S., \& Gehrcke, K. (2014). Outdoor ${ }^{222} \mathrm{Rn}$-concentrations in Germany - part 2 - former mining areas. J. Environ. Radioact., 132, 131-137. http://dx.doi.org/10.1016/j.jenvrad.2014.01.011.

19. OriginLab. (2014). OriginLab [computer software]. Northampton: OriginLab Corporation. Retrieved from http://www.originlab.com/.

20. R Core Team. (2015). R: A language and environment for statistical computing. Vienna, Austria: R Foundation for Statistical Computing. Retrieved from http:// www.r-project.org/.

21. RStudio Team. (2015). RStudio: Integrated development environment for $R$. Boston, MA. Retrieved from http://www.rstudio.com/.

22. Japan Meteorological Agency. (2015). Tables explaining the JMA Seismic Intensity Scale. Retrieved December 21, 2015, from http://www.jma.go.jp/jma/ en/Activities/inttable.html. 